\title{
Satellite-based trends of solar radiation and cloud parameters in Europe
}

\author{
Uwe Pfeifroth $^{1}$, Jedrzej S. Bojanowski ${ }^{2}$, Nicolas Clerbaux ${ }^{3}$, Veronica Manara ${ }^{4}$, \\ Arturo Sanchez-Lorenzo ${ }^{5}$, Jörg Trentmann ${ }^{1}$, Jakub P. Walawender ${ }^{1}$, and Rainer Hollmann ${ }^{1}$ \\ ${ }^{1}$ Satellite-based Climate Monitoring Department, Deutscher Wetterdienst, Offenbach, Germany \\ ${ }^{2}$ Remote Sensing Centre, Institute of Geodesy and Cartography, Warsaw, Poland \\ ${ }^{3}$ Royal Meteorological Institute of Belgium, Remote Sensing from Space, Brussels, Belgium \\ ${ }^{4}$ Institute of Atmospheric Sciences and Climate, ISAC-CNR, Bologna, Italy \\ ${ }^{5}$ Department of Physics, University of Extremadura, Badajoz, Spain \\ Correspondence: Uwe Pfeifroth (uwe.pfeifroth@dwd.de)
}

Received: 3 January 2018 - Revised: 22 March 2018 - Accepted: 10 April 2018 - Published: 18 April 2018

\begin{abstract}
Solar radiation is the main driver of the Earth's climate. Measuring solar radiation and analysing its interaction with clouds are essential for the understanding of the climate system. The EUMETSAT Satellite Application Facility on Climate Monitoring (CM SAF) generates satellite-based, high-quality climate data records, with a focus on the energy balance and water cycle. Here, multiple of these data records are analyzed in a common framework to assess the consistency in trends and spatio-temporal variability of surface solar radiation, top-of-atmosphere reflected solar radiation and cloud fraction. This multi-parameter analysis focuses on Europe and covers the time period from 1992 to 2015. A high correlation between these three variables has been found over Europe. An overall consistency of the climate data records reveals an increase of surface solar radiation and a decrease in top-of-atmosphere reflected radiation. In addition, those trends are confirmed by negative trends in cloud cover. This consistency documents the high quality and stability of the CM SAF climate data records, which are mostly derived independently from each other. The results of this study indicate that one of the main reasons for the positive trend in surface solar radiation since the 1990's is a decrease in cloud coverage even if an aerosol contribution cannot be completely ruled out.
\end{abstract}

\section{Introduction}

Solar radiation is a key parameter in the Earth's climate system (e.g. Hartmann et al., 1986), hence it is essential to observe and analyze the surface solar radiation (SSR) and to understand possible temporal changes (e.g. SanchezLorenzo et al., 2015; Wild, 2016). A general decrease of SSR from the 1950's to the 1980' (global dimming) and an increase since the 1980's (brightening) have been observed (e.g. Ohmura, 2009; Wild, 2009, 2012). In previous studies, changes in the aerosol loading have been concluded to be the main reason for the changes in SSR (e.g. Ruckstuhl et al., 2008; Ruckstuhl and Norris, 2009; Philipona et al., 2009; Zubler et al., 2011; Sanchez-Lorenzo and Wild, 2012; Nabat et al., 2014). Yet, clouds might also play an essential role as they strongly interact with radiation in the troposphere and are another possible reason for changes in SSR (e.g. Long et al., 2009; Parding et al., 2016; Sanchez-Lorenzo et al., 2017a).

SSR and top-of-atmosphere reflected solar radiation (TRS) are physically linked through clouds that reflect solar incoming radiation back to space, which in turn leads to a reduced SSR (Ohmura and Gilgen, 1993). As the density of high-quality station measurements of SSR is low (Ohmura et al., 1998), satellite-based data records are an important complementary data source. Furthermore, measurements of important parameters like TRS are only available from satellite measurements. CM SAF satellite climate records of SSR have shown to be of a high accuracy (e.g. Riihelä et al., 2015; Urraca et al., 2017) and have been used to study climate trends (e.g. Sanchez-Lorenzo et al., 
2017b). Moreover Pfeifroth et al. (2018) has recently shown that CM SAF's climate data records of SSR agree well with station-based SSR measurements concerning variability and trends in Europe.

Satellite-based climate data records of SSR, TRS and cloud fractional coverage (CFC) from the CM SAF affords the opportunity to get new insights into the radiation-cloud interactions and to test the consistency of the satellite-based climate data records. Ultimately, this study aims at a crossconsistency analysis of SSR, TRS and CFC data provided by the CM SAF.

\section{Data}

\subsection{Surface solar radiation}

The SSR data used in this study are the CM SAF's Surface Solar Radiation Dataset - Heliosat, Edition 2 (SARAH-2, Pfeifroth et al., 2017) and the CM SAF Cloud, Albedo And Surface Radiation dataset from AVHRR data, Edition 2 (CLARA-A2, Karlsson et al., 2017a). SARAH-2 is based on the MVIRI and SEVIRI instruments on board of the Meteosat series of geostationary meteorological satellites that cover Europe, Africa, the Atlantic Ocean and parts of South America. By using geostationary satellites, SARAH-2 is based on a temporally consistent $30 \mathrm{~min}$ sampling. CLARAA2 is based on the AVHRR sensor on board of a series of polar orbiting satellites (i.e. NOAA and Metop). CLARAA2 has a global data coverage. Almost for the whole 19922015 period at least two satellites have been used to generate the CLARA-A2 climate data record. However, during winter, the spatial coverage of the CLARA-A2 SSR is not complete due to the limited number of valid observations during daylight especially for latitudes higher than about $55^{\circ} \mathrm{N}$. More information on the SARAH-2 and CLARA-A2 climate data records can be found in Müller et al. (2015a) and Karlsson et al. (2017b), respectively.

\subsection{Top-of-atmosphere reflected solar radiation}

The CM SAF TRS data record (Urbain et al., 2017a) is based on the Meteosat satellite series. The TRS climate data record can be seen as the Top-of-Atmosphere (TOA) counterpart to SARAH-2. Even though both data records are based on the same raw satellite data, the algorithms for data generation are different, starting already from different calibration methods. TRS is defined as the solar radiation reflected by the earthatmosphere system, including gases and aerosols, in addition to scattering by clouds and surface reflections. More information on the TRS data record can be found in Urbain et al. (2017b).

\subsection{Cloud fractional coverage}

The cloud fractional coverage (CFC) data are given by the CM SAF's CLARA-A2 climate data sets (Karlsson et al., 2017a) (cf. Sect. 2.1) and by the CM SAF Cloud Fractional Cover dataset from Meteosat First and Second Generation Edition 1 (COMET, Stöckli et al., 2017). Like the SARAH-2 SSR and TRS data, the COMET CFC climate data record is based on the geostationary Meteosat series. The cloud fractional coverage is bounded between 0 and 100 percentage points, which is simply denoted as $\%$.

\section{Methods}

All data records were used as monthly means during the common time period of 1992-2015 in a European domain on a $0.25^{\circ} \times 0.25^{\circ}$ grid. The conducted variability and trend analysis were generally based on monthly anomalies relative to the corresponding 1992-2015 monthly means. The overall number of data points for each data record is $176 \times 120 \times 288$. The relation between the variables, and the annual and seasonal trends were calculated by applying linear regressions of the anomalies. The correlation was calculated using Pearson's correlation coefficient. A trend is called statistically significant (positive or negative), if both the lower and upper bound of the $95 \%$ confidence interval based on the observations (which reflect a significance level of 0.05 ) are positive or negative.

\section{Trend and variability analysis}

The relation between the different data records and parameters based on the linear regression between all the $\sim 6$ million data points are shown in Table 1. There is overall a high positive correlation of anomalies between the two SSR data records (0.95) and the two CFC data records (0.89). As expected, the SSR and CFC data records are negatively correlated in the range of -0.78 to -0.84 . The correlation of SSR and TRS is also negative of about -0.95 . The correlations of CFC and TRS are in the order of 0.77 to 0.81 , and hence not as high as for the other combinations, likely due to the contribution of the surface reflectivity to the TRS.

It is found that for the time period 1992-2015 the trends of all five analyzed radiation (SSR and TRS) and CFC data records are overall consistent with each other (cf. Figs. 1 and 2). Both SSR data records show an increase and the CFC and TRS data records show a decrease during the analyzed time period. Figure 1 shows the anti-correlation between the CFC/TRS data and the SSR data. The negative COMET CFC trend is less pronounced than the one by CLARA-A2 CFC. Also the general spatial pattern of the trends derived from the different data records agree with each other (cf. Fig. 2). The most positive statistically significant trends in SSR are observed in Eastern and North-Western Europe. The same applies for the corresponding negative trends of CFC and TRS. 
Table 1. Results of the linear regression ( $C=$ Pearson's correlation coefficient, $S=$ slope of regression line) between the monthly anomalies (grid-point wise) of the five data records for the common European domain (shown in Fig. 2). The values refer to the period $1992-2015$.

\begin{tabular}{lcccrr}
\hline \multicolumn{2}{l}{$C=$ correlation; $S=$ slope } & CLARA-A2 SSR & CLARA-A2 CFC & COMET CFC & TOA-TRS \\
\hline \multirow{2}{*}{ SARAH-2 SSR } & $C$ & 0.95 & -0.80 & -0.78 & -0.95 \\
& $S$ & 0.99 & -0.40 & -0.47 & -0.74 \\
\hline \multirow{2}{*}{ CLARA-A2 SSR } & $C$ & & -0.84 & -0.79 & -0.94 \\
& $S$ & & -0.48 & -0.45 & -0.70 \\
\hline \multirow{2}{*}{ CLARA-A2 CFC } & $C$ & & & 0.89 & 0.81 \\
& $S$ & & & 0.87 & 1.02 \\
\hline \multirow{2}{*}{ COMET CFC } & $C$ & & & & 0.77 \\
& $S$ & & & & 1.00 \\
\hline
\end{tabular}

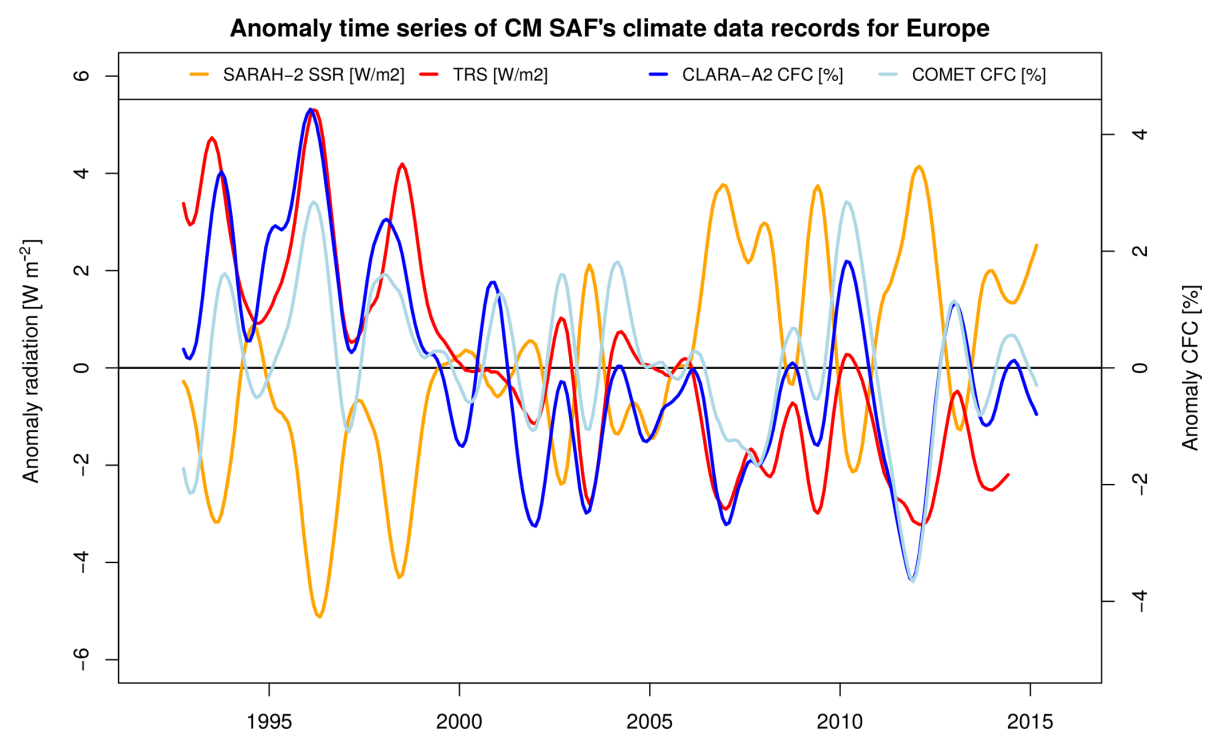

Figure 1. Mean anomaly time series (12-month Gauss-filtered) of SARAH-2 SSR [W m ${ }^{-2}$ ], CLARA-A2 CFC [\%], COMET CFC [\%] and TRS [W m ${ }^{-2}$ ] for the time period 1992-2015. There are two $y$-axis: Radiation [W m ${ }^{-2}$ ] (left) and CFC [\%] (right). Note: CLARA-A2 SSR anomalies are not included due to its incomplete spatial coverage (see Sect. 2.1).

In general, the SSR and CFC trends by the CLARA-A2 climate data record are more pronounced than those given by SARAH-2 SSR and COMET CFC data.

All data records are also compared concerning seasonal trends (see Fig. 3). It is shown that the general consistency of the trends is also valid at the seasonal scale. The largest positive trends in SSR occur in spring in Eastern and North-Western Europe with regionally more than $10 \mathrm{~W} \mathrm{~m}^{-2} \mathrm{decade}^{-1}$, and corresponding negative trends in CFC of up to $-5 \%$ decade $^{-1}$, which is overall in line with the SSR trends found in Sanchez-Lorenzo et al. (2017a). The spatial variability of the trends in the different seasons is quite large. The CFC trends are overall more negative in the CLARA-A2 CFC data record than in the COMET CFC data record. CLARA-A2 SSR trends are overall more positive than the SARAH-2 SSR trends. Differences between the SSR data records exist in winter in parts of Northern and
Eastern Europe, likely due to the difficulties of the SSR retrieval over snow-covered surfaces.

\section{Discussion}

Given the fact that the SSR trends between SARAH-2, CLARA-A2 and surface stations agree well in Europe (Pfeifroth et al., 2018) and that a monthly climatology of aerosol loading is used for the generation of the CM SAF's SSR climate data records, it can be concluded that one of the major reasons of the observed trends in SSR in Europe are changes in clouds. This is confirmed by the climate data records of cloud cover - CLARA-A2 CFC and COMET CFC. It should be noted that changes in aerosol concentration and properties might still play a role through the possible change of the aerosol indirect effect, which can change cloud brightness and life time. However, the temporal 


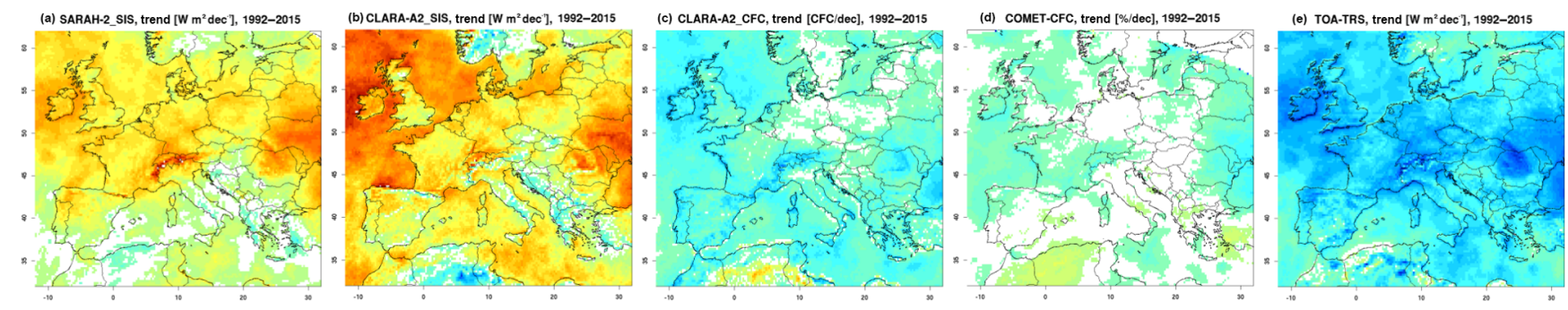

$\begin{array}{lllllllllllllllllllllllllllllllll}-8 & -7.5 & -7 & -6.5 & -6 & -5.5 & -5 & -4.5 & -4 & -3.5 & -3 & -2.5 & -2 & -1.5 & -1 & -0.5 & 0.5 & 1 & 1.5 & 2 & 2.5 & 3 & 3.5 & 4 & 4.5 & 5 & 5.5 & 6 & 6.5 & 7 & 7.5 & 8\end{array}$

Figure 2. Trends (from left to right) of SARAH-2 SSR $\left[\mathrm{W} \mathrm{m}^{-2} \mathrm{decade}^{-1}\right]$, CLARA-A2 SSR [W $\left.\mathrm{m}^{2} \mathrm{decade}^{-1}\right]$, CLARA-A2 CFC [\% decade $\left.{ }^{-1}\right]$, COMET CFC [\% decade $\left.{ }^{-1}\right]$ and TRS $\left[\mathrm{W} \mathrm{m}^{-2}\right.$ decade $^{-1}$ ] for the time period 1992-2015.
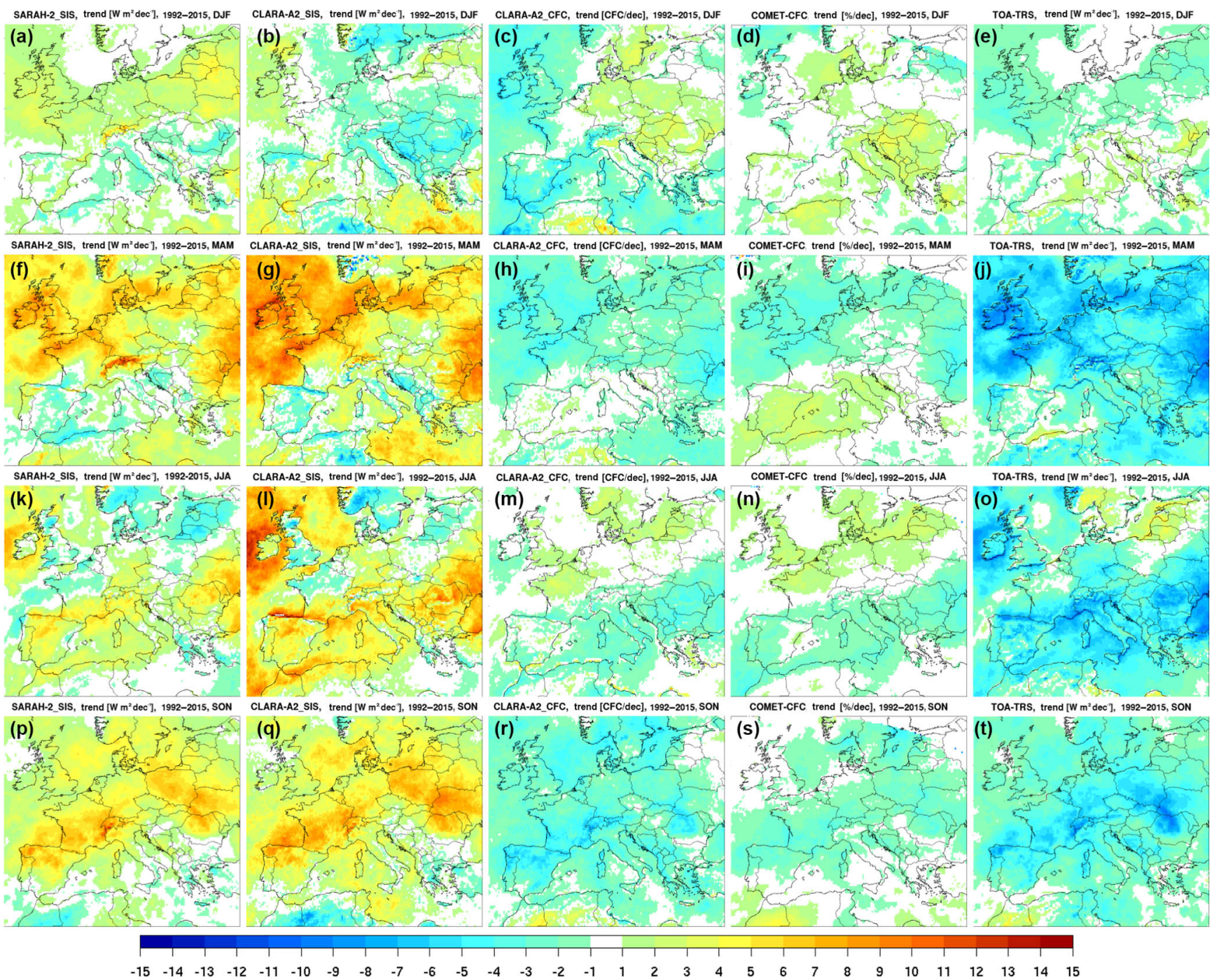

Figure 3. Trends (from left to right) of SARAH-2 SSR $\left[\mathrm{W} \mathrm{m}^{-2} \mathrm{decade}^{-1}\right]$, CLARA-A2 SSR [W m $\left.{ }^{-2} \mathrm{decade}^{-1}\right]$, CLARA-A2 CFC $\left[\%\right.$ decade $\left.^{-1}\right]$, COMET CFC $\left[\%\right.$ decade $\left.^{-1}\right]$ and TRS $\left[\mathrm{W} \mathrm{m}^{-2}\right.$ decade $\left.^{-1}\right]$ for the different seasons (from top to bottom) winter (DJF), spring (MAM), summer (JJA) and autumn (SON). 
variation in the direct aerosol effect is not accounted for by the CM SAF's SARAH-2 and CLARA-A2 SSR data records, except for heavy aerosol events like dust storms (Müller et al., 2015b) and hence an aerosol influence cannot be completely ruled out. In fact, an exception of the good agreement of the satellite-based and station-based trends of SSR has been found in the southern European summer season, when the SSR trends are underestimated by satellite climate data records with reference to station measurements (Pfeifroth et al., 2018), might be due to the higher influence of the aerosol load on SSR in the Mediterranean summer (SanchezLorenzo et al., 2017a; Kambezidis et al., 2016; Nabat et al., 2014).

It should be noted that the CM SAF's climate data records used in this study are mostly derived independently from each other, except for the CLARA-A2 SSR and CFC data records. Even though raw satellite data are partly common, the algorithms - starting from the calibration procedures are different. This fact underlines the significance of the results presented.

\section{Conclusions}

This study shows high correlations between the CM SAF's SSR, CFC and TRS climate data records in Europe, which confirm the high quality of the analyzed CM SAF's climate data records. The SARAH-2 and CLARA-A2 SSR data show an increasing trend in Europe for the analyzed time period of 1992-2015, in line with station observations (SanchezLorenzo et al., 2017a; Pfeifroth et al., 2018). In correspondence, the analysis of the COMET and CLARA-A2 CFC climate data records and the TRS data reveal a negative trend (cf. Fig. 2). The overall consistency is expressed by the agreements in the trend pattern at the annual and seasonal scale. Challenges remain e.g. in case of bright surfaces (i.e. snow cover), that can be misclassified as clouds.

Based on the analysis of the CM SAF's SSR, CFC and TRS climate data records it is indicated that changes in clouds is one of the main drivers for variability and trends in SSR during the time period 1992-2015 in Europe (especially in the northern and central parts). However, effects through aerosols cannot be completely ruled out. In fact, the decrease in aerosol load could have reduced the brightness of clouds and decreased the cloud life time (indirect effect), as well as reduced the direct effect. The latter is more important in southern Europe especially in summer (Pfeifroth et al., 2018, and references therin).

Moreover, clouds are also identified as the main reason for a change in the observed SSR in Europe by Parding et al. (2016) and Mateos et al. (2014), which is however in contrast to other studies (e.g. Philipona et al., 2009; Zubler et al., 2011; Nabat et al., 2014). Further research is needed to further verify possible reasons for the positive trend in SSR in Europe since the 1980's especially in the southern part of Europe. The negative trends in cloud cover over Europe can be due to changes in the tropospheric dynamics, i.e. in the large scale circulation (Trigo et al., 2002), which needs further investigations. Large scale circulation changes might be indicated by an observed negative tendency of the North Atlantic Oscillation Index (Barnston et al., 1987) since the early 1990's (not shown). However, it is very likely that there is no single reason for the observed large scale and long-term change in SSR over Europe, but a combination of different reasons.

Data availability. All analyzed EUMETSAT CM SAF climate data records are freely accessible through the CM SAF Web User Interface (https://wui.cmsaf.eu) and DOI referenced:

- CLARA-A2 (https://doi.org/10.5676/EUM_SAF_CM/ CLARA_AVHRR/V002),

- COMET (https://doi.org/10.5676/EUM_SAF_CM/CFC_ METEOSAT/V001),

- SARAH-2 (https://doi.org/10.5676/EUM_SAF_CM/SARAH/ V002),

- TOA TRS (https://doi.org/10.5676/EUM_SAF_CM/TOA_ MET/V001).

Competing interests. The authors declare that they have no conflict of interest.

Special issue statement. This article is part of the special issue "17th EMS Annual Meeting: European Conference for Applied Meteorology and Climatology 2017". It is a result of the EMS Annual Meeting: European Conference for Applied Meteorology and Climatology 2017, Dublin, Ireland, 4-8 September 2017.

Acknowledgements. The authors would like to thank the data providers for free data access.

Edited by: Ole Einar Tveito

Reviewed by: two anonymous referees

\section{References}

Barnston, A. G. and Livezey, R. E.: Classification, seasonality and persistence of low-frequency atmospheric circulation patterns, Mon. Weather Rev., 115, 1083-1126, 1987.

Hartmann, D. L., Ramanathan, V., Berroir, A., and Hunt, G. E.: Earth Radiation Budget data and climate research, Rev. Geophys., 24, 1944-9208, https://doi.org/10.1029/RG024i002p00439, 1986.

Kambezidis, H. D., Kaskaoutis, D. G., Kalliampakos, G. K., Rashki, A., and Wild, M.: The solar dimming/brightening effect over the Mediterranean Basin in the period 19792012, J. Atmos. Sol.-Terr. Phy., 150-151, 31-46, https://doi.org/10.1016/j.jastp.2016.10.006, 2016. 
Karlsson, K.-G., Anttila, K., Trentmann, J., Stengel, M., Fokke Meirink, J., Devasthale, A., Hanschmann, T., Kothe, S., Jääskeläinen, E., Sedlar, J., Benas, N., van Zadelhoff, G.-J., Schlundt, C., Stein, D., Finkensieper, S., Håkansson, N., Hollmann, R., Fuchs, P., and Werscheck, M.: CLARA-A2: CM SAF cLoud, Albedo and surface RAdiation dataset from AVHRR data - Edition 2, Satellite Application Facility on Climate Monitoring, https://doi.org/10.5676/EUM_SAF_CM/CLARA_AVHRR/V002, $2017 \mathrm{a}$.

Karlsson, K.-G., Anttila, K., Trentmann, J., Stengel, M., Fokke Meirink, J., Devasthale, A., Hanschmann, T., Kothe, S., Jääskeläinen, E., Sedlar, J., Benas, N., van Zadelhoff, G.J., Schlundt, C., Stein, D., Finkensieper, S., Håkansson, N., and Hollmann, R.: CLARA-A2: the second edition of the CM SAF cloud and radiation data record from 34 years of global AVHRR data, Atmos. Chem. Phys., 17, 5809-5828, https://doi.org/10.5194/acp-17-5809-2017, 2017b.

Long, C. N., Dutton, E. G., Augustine, J. A., Wiscombe, W., Wild, M., McFarlane, S. A., and Flynn, C. J.: Significant decadel brightening of downwelling shortwave in the continental United States, J. Geophys. Res., 114, D00D06, https://doi.org/10.1029/2008JD011263, 2009.

Mateos, D., Sanchez-Lorenzo, A., Antón, M., Cachorro, V. E., Calbó, J., Costa, M. J., Torres, B., and Wild, M.: Quantifying the respective roles of aerosols and clouds in the strong brightening since the early 2000s over the Iberian Peninsula, J. Geophys. Res.-Atmos., 119, 10382-10393, https://doi.org/10.1002/2014JD022076, 2014.

Müller, R., Pfeifroth, U., Traeger-Chatterjee, C., Trentmann, J., and Cremer, R.: Digging the METEOSAT Treasure-3 Decades of Solar Surface Radiation, Remote Sensing, 7, 8067-8101, https://doi.org/10.3390/rs70608067, 2015a.

Müller, R., Pfeifroth, U., and Traeger-Chatterjee, C.: Towards Optimal Aerosol Information for the Retrieval of Solar Surface Radiation Using Heliosat, Atmosphere, 6, 863-878, https://doi.org/10.3390/atmos6070863, 2015b.

Nabat, P., Somot, S., Mallet, M., Sanchez-Lorenzo, A., and Wild, M.: Contribution of anthropogenic sulfate aerosols to the changing Euro-Mediterranean climate since 1980, Geophys. Res. Lett., 41, 5605-5611, https://doi.org/10.1002/2014GL060798, 2014.

Ohmura, A.: Observed decadal variations in surface solar radiation and their causes, J. Geophys. Res., 114, D00D05, https://doi.org/10.1029/2008JD011290, 2009.

Ohmura, A. and Gilgen, H.: Re-Evaluation of the Global Energy Balance, in: Interactions Between Global Climate Subsystems the Legacy of Hann, edited by: McBean G. A. and Hantel, M., American Geophysical Union, Washington, D.C., https://doi.org/10.1029/GM075p0093, 1993.

Ohmura, A., Dutton, E. G., Forgan, B., Frohlich, C., Gilgen, H., Hegner, H., Heimo, A., König-Langlo, G., McArthur, B., Muller, G., Philipona, R., Pinker, R., Whitlock, C. H., Dehne, K., and Wild, M.:Baseline Surface Radiation Network (BSRN/WCRP): New precision radiometry for climate research, B. Am. Meteorol. Soc., 79, 2115-2136, https://doi.org/10.1175/15200477(1998)079<2115:BSRNBW>2.0.CO;2, 1998.

Parding, K. M., Liepert, B. G., Hinkelmann, L. M., Ackerman, T. P., Dagestad, K.-F., and Olseth, J. A.: Influence of Synoptic Weather Patterns on Solar irradiance Variability in Northern Eu- rope, J. Climate, 29, 4229-4250, https://doi.org/10.1175/JCLID-15-0476.1, 2016.

Pfeifroth, U., Kothe, S., Müller, R., Trentmann, J., Hollmann, R., Fuchs, P, and Werscheck, M.: Surface Radiation Data Set - Heliosat (SARAH) - Edition 2, Satellite Application Facility on Climate Monitoring, https://doi.org/10.5676/EUM_SAF_CM/SARAH/V002, 2017.

Pfeifroth, U., Sanchez-Lorenzo, A., Manara, V., Trentmann, J., and Hollmann, R.: Trends and Variability of Surface Solar Radiation in Europe based on Surface- and Satellite-based Data Records, J. Geophys. Res.-Atmos., 123, 1735-1754, https://doi.org/10.1002/2017JD027418, 2018.

Philipona, R., Behrens, K., and Ruckstuhl, C.: How declining aerosols and rising greenhouse gases forced rapid warming in Europe since the 1980s, Geophys. Res. Lett., 36, L02806, https://doi.org/10.1029/2008GL036350, 2009.

Riihelä, A., Carlund, T., Trentmann, J., Müller, R., and Lindfors, A. V.: Validation of CM SAF Surface Solar Radiation Datasets over Finland and Sweden, Remote Sensing, 7, 66636682, https://doi.org/10.3390/rs70606663, 2015.

Ruckstuhl, C. and Norris, J. R.: How do aerosol histories affect solar "dimming" and "brightening" over Europe: IPCC-AR4 models versus observations, J. Geophys. Res., 114, D00D04, https://doi.org/10.1029/2008JD011066, 2009.

Ruckstuhl, C., Philipona, R., Behrens, K., Collaud Coen, M., Dürr, B., Heimo, A., Mätzler, C., Nyeki, S., Ohmura, A., Vuilleumier, L., Weller, M., Wehrli, C., and Zelenka, A.: Aerosol and cloud effects on solar brightening and the recent rapid warming, Geophys. Res. Lett., 35, L12708, https://doi.org/10.1029/2008GL034228, 2008.

Sanchez-Lorenzo, A. and Wild, M.: Decadal variations in estimated surface solar radiation over Switzerland since the late 19th century, Atmos. Chem. Phys., 12, 8635-8644, https://doi.org/10.5194/acp-12-8635-2012, 2012.

Sanchez-Lorenzo, A., Wild, M., Brunetti, M., Guijarro, J. A., Hakuba, M. Z., Calbó, J., Mystakidis, S., and Bartók, B.: Reassessment and update of long-term trends in downward surface shortwave radiation over Europe (1939-2012), J. Geophys. Res.-Atmos., 120, 2169-8996, https://doi.org/10.1002/2015JD023321, 2015.

Sanchez-Lorenzo, A., Enriquez-Alonso, A., Calbó, J., González, J.A., Wild, M., Follini, D., Norris, J. R., and Vincente-Serrano, S. M.: Fewer clouds in the Mediterranean: consistency of observations and climate simulations, Scient. Rep., 7, 41475, https://doi.org/10.1038/srep41475, 2017a.

Sanchez-Lorenzo, A., Enriquez-Alonso, A., Wild, M., Trentmann, J., Vincente-Serrano, S. M., Sanchez-Romero, A., Posselt, R., and Hakuba, M.: Trends in downward surface solar radiation from satellites and ground observations over Europe during 1983-2010, Remote Sens. Environ., 189, 108-117, https://doi.org/10.1016/j.rse.2016.11.018, 2017b.

Stöckli, R., Duguay-Tetzlaff, A., Bojanowski, J., Hollmann, R., Fuchs, P., and Werscheck, M.: CM SAF ClOud Fractional Cover dataset from METeosat First and Second Generation - Edition 1 (COMET Ed. 1), Satellite Application Facility on Climate Monitoring, https://doi.org/10.5676/EUM_SAF_CM/CFC_METEOSAT/V001, 2017. 
Trigo, R. M., Osborn, T. J., and Corte-Real, J. M.: The North Atlantic Oscillation influence on Europe: climate impacts and associated physical mechanisms, Clim. Res., 20, 9-17, https://doi.org/10.3354/cr020009, 2002.

Urbain, M., Clerbaux, N., Ipe, A., Tornow, F., Hollmann, R., Baudrez, E., Blazquez, A. V., and Moreels, J.: The CM SAF TOA Radiation Data Record Using MVIRI and SEVIRI, Remote Sensing, 9, 466, https://doi.org/10.3390/rs9050466, 2017a.

Urbain, M., Clerbaux, N., Ipe, A., Tornow, F., Hollmann, R., Fuchs, P., and Werscheck, M.: Top of Atmosphere Radiation MVIRI/SEVIRI Data Record, Satellite Application Facility on Climate Monitoring, https://doi.org/10.5676/EUM_SAF_CM/TOA_MET/V001, $2017 b$.

Urraca, R, Gracia-Amillo, A. M., Koubli, E., Huld, T., Trentmann, J., Riihelä, A., Lindfors, A. V., Palmer, D., Gottschalg, R., and Antonanzas-Torres, F.: Extensive validation of CM SAF surface radiation products over Europe, Remote Sens. Environ., 199, 171-186, https://doi.org/10.1016/j.rse.2017.07.013, 2017.
Wild, M.: Global dimming and brightening: A review, J. Geophys. Res.-Atmos., 114, 2156-2202, https://doi.org/10.1029/2008JD011470, 2009.

Wild, M.: Enlightening Global Dimming and Brightening, B. Am. Meteorol. Soc., 93, 27-37, https://doi.org/10.1175/BAMS-D-1100074.1.

Wild, M.: Decadal changes in radiative fluxes at land and ocean surfaces and their relevance for global warming, Wiley Interdisc. Rev.: Clim. Change, 7, 91-107, https://doi.org/10.1002/wcc.372, 2016.

Zubler, E. M., Folini, D., Lohmann, U., Lüthi, D., Schär, C., and Wild, M.: Simulation of dimming and brightening in Europe from 1958 to 2001 using a regional climate model, J. Geophys. Res., 116, D18205, https://doi.org/10.1029/2010JD015396, 2011. 